\title{
Local Failure and Margin Status in Early-Stage Breast Carcinoma Treated with Conservation Surgery and Radiation Therapy
}

Mitchell S. Anscher, M.D., * Patricia Jones, M.D., || Leonard R. Prosnitz, M.D., ${ }^{*}$ William Blackstock, M.D., || Mary Hebert, M.D., ${ }^{*}$ Robert Reddick, M.D., I Allan Tucker, M.D., $\dagger$ Richard Dodge, M.S., $\ddagger$ George Leight, Jr., M.D.,§ J. Dirk Iglehart, M.D.,§ and Julian Rosenman, Ph.D., M.D.\|'\#

From the Departments of Radiation Oncology, ${ }^{*}$ Pathology, $†$ Community and Family Medicine, $\ddagger$ Biometry and Medical Information Division, and Surgery, $§$ Duke University Medical Center, Durham, and the Departments of Radiation Oncology, \| Pathology, $\|$ and Computer Science,\# the University of North Carolina at Chapel Hill, Chapel Hill, North Carolina

\section{Objective}

The authors determined whether microscopically positive surgical margins are detrimental to the outcome of early stage breast cancer patients treated with conservation surgery and radiation therapy.

\section{Summary Background Data}

The optimal extent of breast surgery required for patients treated with conservation surgery and radiation therapy has not been established. To achieve breast preservation with good cosmesis, it is desirable to resect as little normal tissue as possible. However, it is critical that the resection does not leave behind a tumor burden that cannot be adequately managed by moderate doses of radiation. It is not known whether microscopically positive surgical margins are detrimental to patient outcome.

\section{Methods}

The records of 259 consecutive women (262 breasts) treated with local excision (complete removal of gross tumor with a margin) and axillary dissection followed by radiation therapy for clinical stage I and II infiltrating ductal breast cancer at Duke University Medical Center and the University of North Carolina between 1983 and 1988 were reviewed. Surgical margins were considered positive if tumor extended to the inked margins; otherwise the margins were considered negative. Margins that could not be determined, either because the original pathology report did not comment on margins, or because the original specimen had not been inked were called indeterminate.

\section{Results}

Of the 262 tumors, $32(12 \%)$ had positive margins, $132(50 \%)$ had negative margins, and the remaining $98(38 \%)$ had indeterminate margins. There were $11(4 \%)$ local failures; $3 / 32(9 \%)$ from the positive margin group, $2 / 132(1.5 \%)$ from the negative margin group, and $6 / 98(6 \%)$ from the indeterminate group. The actuarial local failure rates at 5 years were $10 \%, 2 \%$, and 
$10 \%$, respectively, $p=0.014$ positive vs. negative, $p=0.08$ positive vs. indeterminate (log rank test). Margin status had no impact on survival or freedom from distant metastasis; 63 patients who originally had positive or indeterminate margins were re-excised. Two of 7 with positive margins after re-excision versus 1/56 rendered margin negative had a local recurrence.

\section{Conclusions}

The authors recommend re-excision for patients with positive margins because of improved local control of those rendered margin negative and identification of those patients at high risk for local failure (those who remain positive after re-excision). Because margin status impacts on local control, tumor margins after conservation surgery should be accurately determined in all patients.

Definitive radiation after conservation surgery for early-stage breast cancer is an established alternative to mastectomy for a defined patient population. The National Institutes of Health Consensus Conference in January 1991 recommended breast conservation treatment as the preferred method of primary therapy for "... the majority of women with stage I and II breast cancer ..."1

Breast conservation surgery has been defined as complete excision of the primary tumor and adjacent breast tissue with or without axillary dissection. However, the optimal extent of the breast surgery required for patients treated with definitive irradiation has not been established. Since the rationale for breast conservation surgery is breast preservation with good cosmesis, it is desirable to resect as little normal tissue as possible. On the other hand it is critical that the resection does not leave behind a tumor burden that cannot be adequately managed by moderate doses of radiation. It is not known whether microscopically positive surgical margins are detrimental to patient outcome; the literature is contradictory on this subject. ${ }^{2-12}$ To derive further information, we undertook a retrospective review of all clinical stage I and II patients treated at Duke University Medical Center (DUMC) and the University of North Carolina Hospitals $(\mathrm{UNCH})$ with conservative surgery and radiation therapy.

\section{MATERIALS AND METHODS}

The records of 259 consecutive women (262 breasts) treated with local excision (complete removal of gross tumor with a margin) and axillary dissection followed by radiation therapy for invasive breast carcinoma at Duke University Medical Center and the University of North Carolina between 1983-1988 were evaluated. This represents all patients with clinical stage I and II infiltrating

\footnotetext{
Address reprint requests to Mitchell Anscher, M.D., Department of Radiation Oncology, Box 3085, Duke University Medical Center, Durham, NC 27710

Accepted for publication April 17, 1992.
}

ductal breast cancer treated with conservation surgery and radiation therapy at the two institutions over this time period. Patients whose surgery was performed elsewhere, but who were irradiated at either of the two medical centers (or affiliates) were included in the analysis.

A pathologic review of the original tumor slides in 137 of the 262 breasts was undertaken by a pathologist in each institution (RR and AT). Slides were randomly exchanged and cross-read by pathologists from both institutions. In the few cases in which there was disagreement between the pathologists, the findings were discussed and a consensus was reached. On a few occasions, surgical specimens were recut for further analysis of an inked margin. Non-inked specimens available for review were not recut since these were, by definition, indeterminate (see below).

The practice of inking surgical specimens for margin analysis varied over the years of the study. Few specimens from outside institutions were routinely inked. At both DUMC and UNCH, specimens were not routinely inked until the later years of the study. Margins were considered positive if tumor extended to the inked margin; otherwise the margins were considered negative. The original pathology report was considered definitive for the 125 cases in which the slides were not available for review. If the patient had undergone a re-excision of the primary site, the final pathology report was the one used to determine marginal status. For example, if the original resection margin was pathologically positive and no tumor was identified in the re-excision specimen, the patient was considered to have negative margins. Margins that could not be determined, either because the original pathology report did not comment on margins, or because the original specimen had not been inked were called indeterminate.

Clinical data collected included age, $\mathrm{T}$ and $\mathrm{N}$ stage (clinical and pathological), radiation dose to the breast and tumor bed, adjuvant therapy received, hormonal receptor status, presence or absence of extensive intraductal carcinoma (EIC) in the lumpectomy specimen and patient outcome with respect to local control, survival, freedom from distant disease, and disease free survival. 
EIC was defined according to the criteria of Schnitt. ${ }^{13}$ Local failure only was defined as a recurrence in the treated breast without regional or distant metastases. Regional failure was defined as failure in the ipsilateral axillary, infraclavicular, supraclavicular, or internal mammary nodes without distant metastases. Local and regional failure was defined as simultaneous failure in the breast and regional nodes without distant metastases. All other sites of failure were considered distant metastases. New cancers arising in the opposite breast were considered second primaries, not recurrences.

All patients were treated with external beam radiation and most had boosts with either electrons or interstitial ${ }^{192} \mathrm{Ir}$. Axillary nodes were not irradiated after axillary dissection unless there was extensive axillary nodal involvement. Treatment of internal mammary and supraclavicular nodes varied by institution and also with time, elective treatment of internal mammary and supraclavicular nodes being less common at UNCH than at DUMC. These draining nodal groups were treated only in patients whose axillary status was unknown or positive. Total breast doses ranged from 43.2 to 50.4 Gy except for two patients who received 30 and $42 \mathrm{~Gy}$. Total tumor bed doses ranged from 42 to 71 Gy. (Fig. 1, Table 1). All treatments were given with megavoltage energies with daily fractions ranging from 1.8 to $2.0 \mathrm{~Gy} /$ day 5 days per week.

Adjuvant therapy, during the years of this study, whether cytotoxic or hormonal, was usually reserved for node positive patients.

Patients were involved in follow-up by both their surgeon and radiation oncologist at 3-month intervals for the first 2 years, and semiannually thereafter. Mammograms were obtained at least once per year after treatment. Other radiographic or laboratory tests were obtained only as needed. This schedule was used by both institutions.

Survival and local control curves were estimated by the method of Kaplan and Meier. ${ }^{14}$ The log-rank test ${ }^{15}$ was used to compare survival distributions.

To detect significant prognostic factors, a univariate Cox regression analysis ${ }^{16}$ was performed to study the predictive information available in each variable acting independently. This was followed by a multivariate regression analysis performed in a step-wise manner entering initially the most significant prognostic factors.

\section{RESULTS}

Of excisions in 262 breasts, $32(12 \%)$ had positive margins, $132(50 \%)$ had negative margins, and the remaining $98(38 \%)$ had indeterminate margins. Median follow-up for all patients was 44 months. There were $11(4 \%)$ local

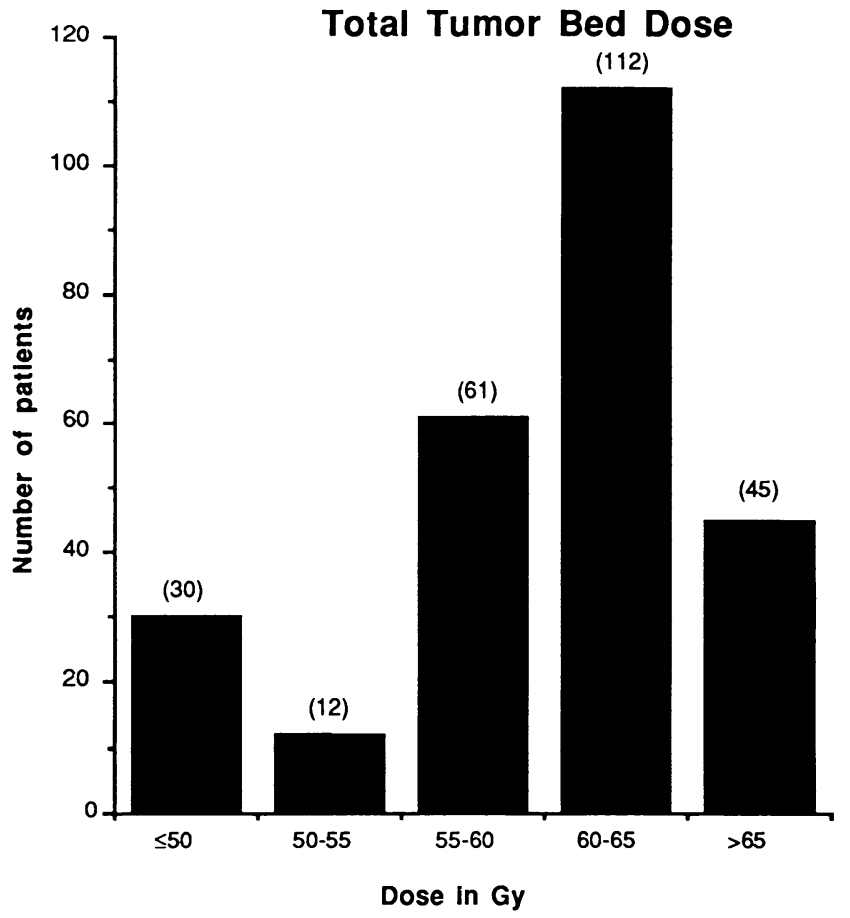

Figure 1. Histogram of total tumor bed dose (breast dose plus implant). Median dose was 62 Gy.

failures overall in the breast: $3 / 32(9 \%)$ from the positive margin group, $2 / 132(1.5 \%)$ from the negative margin group, and $6 / 98(6 \%)$ from the indeterminate group. The actuarial local failure rates at 5 years were $10 \%, 2 \%$, and $10 \%$ respectively $(\mathrm{p}=0.014$ positive vs. negative, $\mathrm{p}$ $=0.08$ positive vs. indeterminate, log-rank test) (Fig. 2).

On pathologic review, approximately $20 \%$ of the cases originally classified as having positive or negative margins had their margin status reversed ( $2 / 7$ positive to negative, $7 / 36$ negative to positive). Of the group previously called indeterminate, it was possible to assign a margin status to 50/94 (35 negative, 15 positive). Of the 125 cases not available for review, margins were positive in 3 (2\%), negative in $53(42 \%)$ and indeterminate in $69(56 \%)$.

The characteristics of the positive, negative, and indeterminate margin patients are compared in Table 1. The positive and negative margin patients were similar in all respects. The indeterminate margin group had a higher percentage of positive nodes, and a lower percentage of an extensive intraductal component (EIC) to the tumor than the other two groups.

Of special interest are the 63 patients who originally had positive or indeterminate margins who were re-excised. Seven re-excisions had persistently positive margins $(+\rightarrow+)$, the remaining 56 were negative $(+\rightarrow-)$. The local failure rate in the $+\longrightarrow+$ group was $2 / 7(28 \%)$ versus $1 / 56(2 \%)$ in the $+\rightarrow-$ group. The local failure of the 76 patients with negative margins at first excision 
Table 1. PATIENT CHARACTERISTICS

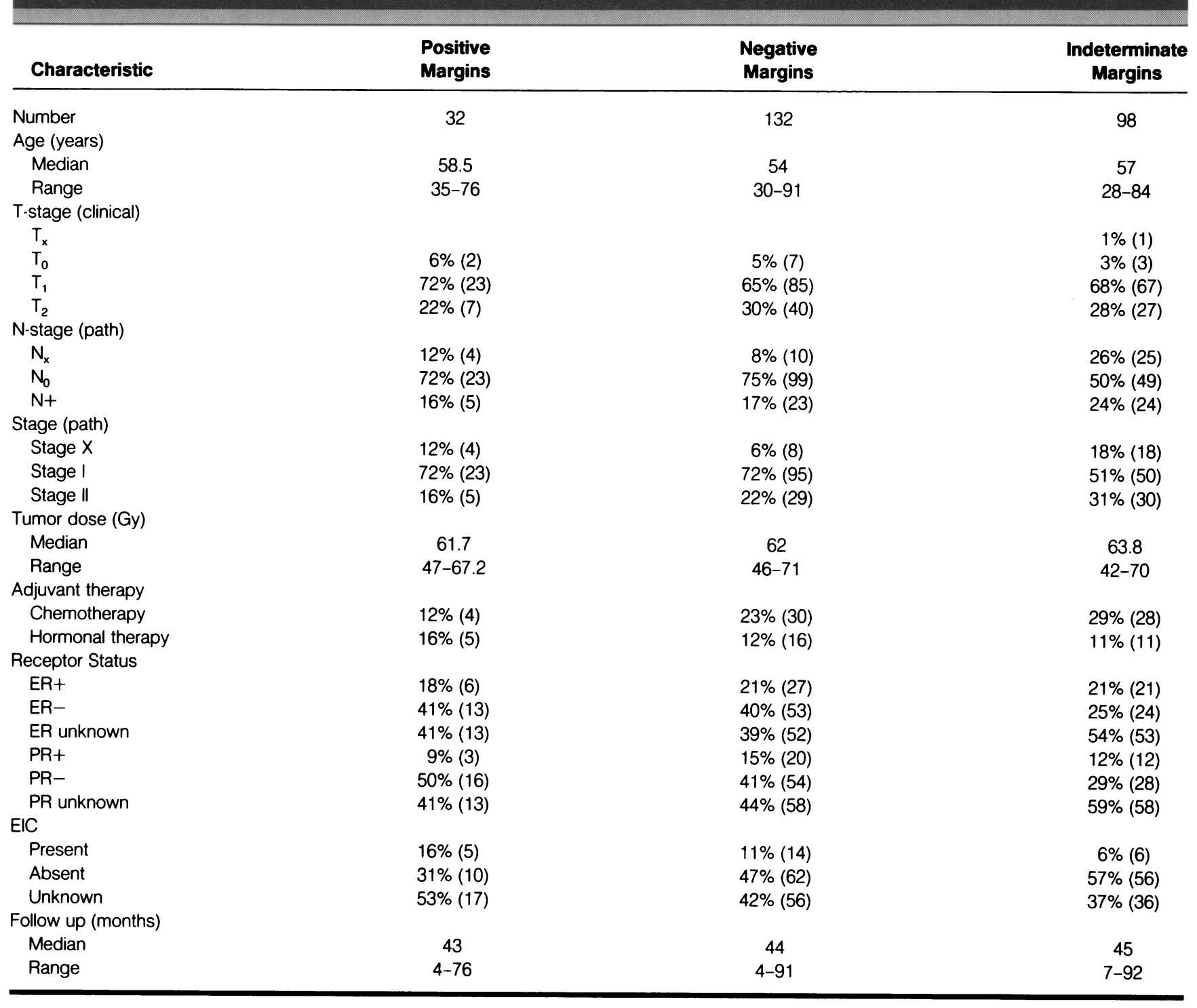

was $1 / 76(1.5 \%)$, no different than the patients rendered negative with re-excision.

The presence of EIC was found to be a significant predictor of local failure with a univariate analysis, but not when controlling for marginal status using a multivariate analysis.

There was no difference between those patients who failed locally and those who did not, with respect to use of systemic therapy, tumor size, nodal status, and radiation dose or other factors listed in Table 1.

After accounting for the difference in nodal status between the groups, margin status had no significant impact on survival, disease-free survival, or freedom from distant metastases. The results of the multivariate analysis indicated that only nodal status affected survival.

\section{DISCUSSION}

Many retrospective studies involving thousands of patients with Stage I or II breast cancer have demonstrated that conservation surgery and radiation therapy produce disease-free survival rates comparable to classical or modified radical mastectomy. ${ }^{17-26}$ Ten-year actuarial local control rates are $80 \%-90 \% .{ }^{27}$ This is similar to rates recorded from surgical series. ${ }^{27-29}$ These results have been confirmed by at least six prospective randomized trials. ${ }^{30,31}$

Older studies have shown the importance of excising the primary tumor before definitive radiation therapy. For example, Calle ${ }^{32}$ reported a local failure rate of $59 \%$ in 384 patients treated exclusively with radiation after 
Local Control for Patients with Positive, Negative, or Unknown Marginal Status

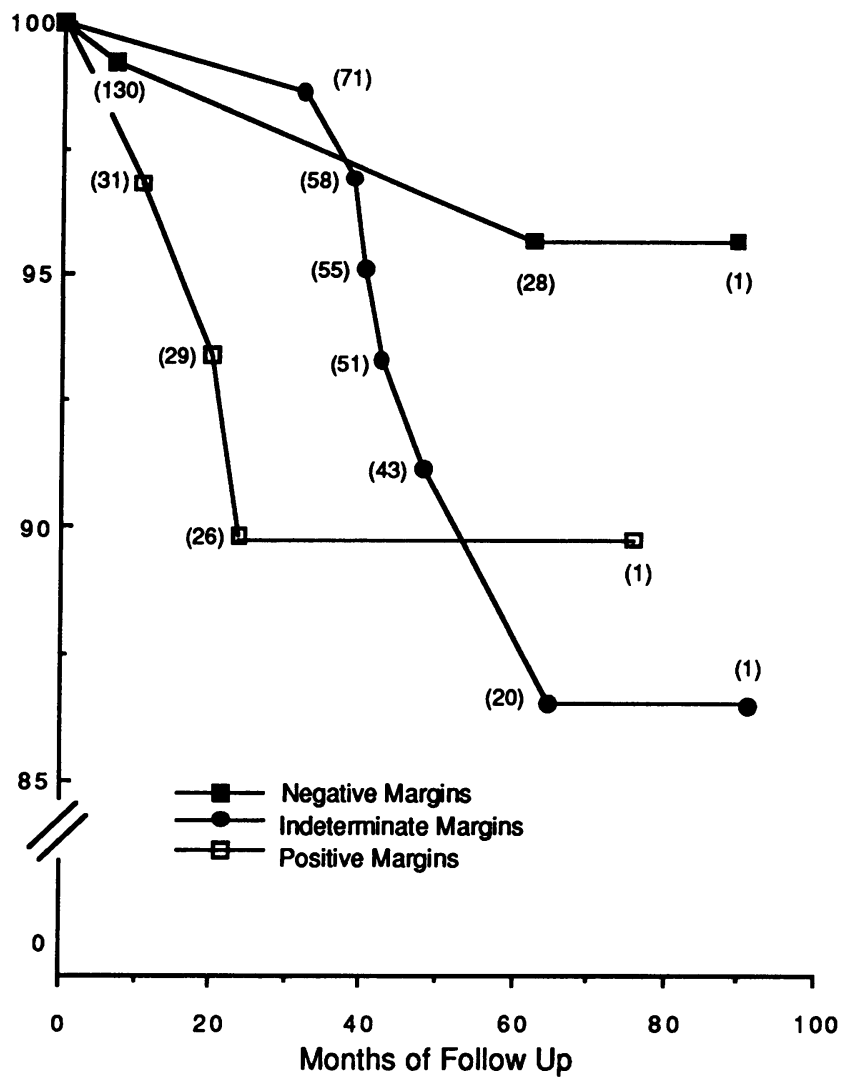

Figure 2. Local control versus marginal status. The negative margin patients did statistically better than the positive margin patients $(p=0.014$, log rank test).

incisional biopsy. Amalric et al. ${ }^{18}$ reported a local-regional failure rate of $38 \%$ in their series. Both studies achieved superior local-regional control when a local excision was performed before irradiation.

Although leaving gross residual tumor before irradiation is detrimental to the outcome, much less is known about the need for obtaining microscopically negative margins. The data are conflicting, with five series showing no increase in breast recurrence with positive margins, ${ }^{2-4,6,7}$ and five showing a higher recurrence rate if margins are positive $\mathrm{e}^{5,8-10,12}$ (Table 2 ). In the largest study, Solin $^{2}$ found that local failure, relapse-free survival, and survival rates were not influenced by marginal status. Nevertheless he recommends re-excision, if possible, to achieve histologically negative margins. The rationale for this recommendation is unclear.

We had 20\% reversal of margin status on review. Given that historically no standards were established for classifying breast tumor excisions as "positive" nor "negative" it is not surprising that $1 / 5$ of the tumor margins were reclassified. We can find no published reports with which to compare our reclassification rate. It is unfortu- nate that 125 cases were not available for review. However, an analysis of our data using only the original margin classification did not yield different results. Our experience suggests that more consistent methods of determining margin status are needed.

Our high rate of local recurrence in patients who had positive margins after re-excision (2/7) suggests that these patients might best be treated with mastectomy. However, patients with initially positive (or indeterminate) excision margins who were rendered margin negative did well ( $1 / 56$ local failures). It is not clear whether the act of re-excision in these patients is therapeutic or diagnostic, in the sense that it identifies patients at extraordinarily high risk for local failure with conservative surgery and radiation. However, we believe that the identification of these patients, alone, is justification for re-excising positive margin patients.

Perhaps the most well-known prognostic factor for predicting local failure after conservative surgery and radiation is the presence of extensive intraductal carcinoma (EIC) as defined by Schnitt. ${ }^{13}$ The data are conflicting. For example, Fisher ${ }^{33}$ found no correlation between EIC and local recurrence in his review of the NSABP trial Protocol 6.

In our study both EIC and marginal status were found to be prognostic for local failure with a univariate analysis. However, the importance of EIC was eliminated when a multivariate analysis was done. Unfortunately only 5 of 11 studies in the literature that reported on the effects of positive margins controlled for the presence of EIC with appropriate multivariate analyses. ${ }^{5,6,8-10}$ Like us, Zafrani ${ }^{9}$ found that marginal status was important, but EIC was not. In the other four studies, three did not ink their specimens ${ }^{5,9,10}$ and one adopted an unusual definition of "positive margins." 8 Thus the studies in the literature differ in their definitions of positive margins and whether a multivariate analysis was used. A standard definition for what constitutes a positive margin would be most helpful. Our use of the term "positive margin" means cancer cells at the inked edge and is in accordance with the NSABP usage. Tumor $1 \mathrm{~mm}$ away from the edge is considered "negative." When the lack of good pathologic data (non-inked specimens) and variation in boost radiation dose are also considered, it is not surprising that studies arrive at conflicting conclusions.

The goal of conservation surgery and radiation is to provide the patient with a treatment as effective as mastectomy with the added benefit of good cosmesis. One of the factors that has been shown to adversely affect the cosmetic result is the amount of breast tissue removed. ${ }^{34,35}$ Thus, the amount of breast tissue removed should be limited to optimize cosmesis.

On the other hand, cosmesis should not be emphasized at the expense of either local recurrence or survival. 
Table 2. FACTORS AFFECTING LOCAL CONTROL OF BREAST CANCER AFTER LUMPECTOMY AND RADIATION

\begin{tabular}{|c|c|c|c|c|c|}
\hline Study & Margins & EIC & $\begin{array}{l}\text { Multivariate } \\
\text { Analysis? }\end{array}$ & Other Factors & Comments \\
\hline Solin ${ }^{2}$ & No & $\mathrm{N} / \mathrm{S}$ & No & N/S & Authors still recommend re-excision. \\
\hline Clarke $^{3}$ & No & $\mathrm{N} / \mathrm{S}$ & No & $\begin{array}{l}\text { Histologic grade, time between } \\
\text { biopsy and } \mathrm{RT} \text {, and breast } \\
\text { radiation dose }\end{array}$ & $\begin{array}{l}\text { Only presence or absence of DCIS } \\
\text { considered, not extent. }\end{array}$ \\
\hline $\begin{array}{l}\text { Schmidt- } \\
\text { Ullrich }^{4}\end{array}$ & No & No & No & $\mathrm{N} / \mathrm{S}$ & $\begin{array}{l}\text { Positive margins defined as } \leq 2 \\
\text { mm. Reexcised patients still } \\
\text { considered positive. }\end{array}$ \\
\hline Kurtz ${ }^{5}$ & Yes & Yes & Yes & $\begin{array}{l}\text { Major lymphocytic reaction and } \\
\text { histologic grade }\end{array}$ & Specimens not inked. \\
\hline Bartelink $^{6}$ & No & Yes & Yes & Age & $\begin{array}{l}\text { All patients with EIC and recurrence } \\
\text { had positive or doubtful margins }\end{array}$ \\
\hline Hunig $^{7}$ & No & N/A & No & N/A & \\
\hline Ryoo $^{8}$ & $\begin{array}{l}\text { Yes, but only if } \\
\text { no boost }\end{array}$ & No & Yes & Age, ER negative & $\begin{array}{l}\text { Positive margins defined as } \leq 5 \\
\mathrm{~mm} \text {. }\end{array}$ \\
\hline Zafrani $^{9}$ & Yes & No & Yes & Lymphatic invasion. & $\begin{array}{l}\text { Specimens not inked. Definition of } \\
\text { EIC more restrictive than Schnitt }\end{array}$ \\
\hline Fourquet $^{10}$ & Yes & No & Yes & $\begin{array}{l}\text { Age, endolymphatic extension of } \\
\text { tumor }\end{array}$ & Specimens not inked \\
\hline Pezner ${ }^{11}$ & Unclear & $\mathrm{N} / \mathrm{S}$ & No & $\mathrm{N} / \mathrm{S}$ & $\begin{array}{l}\text { Difference between negative } \\
\text { margin with no boost, and } \\
\text { unknown margin patients only. }\end{array}$ \\
\hline Hallahan ${ }^{12}$ & Probably yes & $\mathrm{N} / \mathrm{S}$ & No & N/S & $P$-values not given. \\
\hline Present study & Yes & No & Yes & None & \\
\hline
\end{tabular}

The evidence to date suggests that an isolated local recurrence in the breast does not adversely influence patient survival, ${ }^{3,5,10}$ but with longer follow-up, differences may become apparent. Furthermore, local relapse usually requires that the patient undergo mastectomy. On a number of grounds, it is desirable to minimize the risk of breast recurrence. Re-excision of positive or indeterminate margin patients appears to be helpful in this regard, according to our data.

In conclusion, we recommend re-excision for patients undergoing breast conservation therapy in whom the original excisional margins are positive or indeterminate. Local control may be improved if negative margins can be obtained and a cohort of patients at increased risk for local failure (those with positive margins on re-excision) can be identified. Since, local failure carries at least a theoretical risk of increasing the chance of distant metastases, care should be taken by surgeons and pathologists to process lumpectomy specimens appropriately to obtain the necessary information concerning margins.

\section{Acknowledgments}

The authors thank Robert Clough for assistance with data acquisition, and Jane Hoppenworth for manuscript typing.

\section{References}

1. NIH Consensus Conference. Treatment of early-stage breast cancer. JAMA 1991; 265:391-395.

2. Solin LJ, Fowble BL, Schultz DJ, Goodman RL. The signiticance of the pathology margins of the tumor excision on the outcome of patients treated with definitive irradiation for early stage breast cancer. Int J Radiat Oncol Biol Phys 1991; 21:279-287.

3. Clarke D, Le MG, Sarrazin D, Lacombe M, Fontaine F, et al. Analysis of local-regional relapses in patients with early breast cancers treated by excision and radiotherapy: experience of the Institute Gustave-Roussy. Int J Radiat Oncol Biol Phys 1985; 11:137-145.

4. Schmidt-Ullrich R, Wazer D, Tercilla O, Safai H, Marchant DJ, et al. Tumor margin assessment as a guide to optimal conservation surgery and irradiation in early stage breast carcinoma. Int J Radiat Oncol Biol Phys 1989; 17:733-738.

5. Kurtz JN, Jacquemier J, Amalric K, Brandone H, Anmy Y, et al. Why are local recurrences after breast conserving surgery more frequent in young patients? J Clin Oncol 1990; 8:591-598.

6. Bartelink H, Borger JH, van Dongen JA, Peters JL. The impact of tumor size and histology on local control after breast conserving therapy. Radiother Oncol 1988; 11:297-303.

7. Hunig R, Walther E, Harder FH, Almendral AC, Roth J, Torhorst J. The Basel lumpectomy protocol: five year experience with a prospective study for conservative treatment of breast cancer. In Harris J, Hellman S, Silen W, eds. Conservative Management of Breast Cancer. Philadelphia: J.B. Lippincott Co, 1983, pp 23-33.

8. Ryoo MC, Kagan AR, Woolin M, Tome MA, Tedeschi MA, et al. Prognostic factors for recurrence and cosmesis in 393 patients after radiation therapy for early mammary carcinoma. Radiology 1989 ; 172:555-559. 
9. Zafrani B, Vielh P, Fourquet A, Mosseri V, Durand JC, et al. Conservative treatment of early breast cancer: prognostic value of ductal in situ component and other pathological variables on local control and survival. Eur J Cancer Clin Oncol 1989; 25:16451650.

10. Fourquet A, Campana F, Zafrani B, Mosseri V, Vielh P, Durand JC, Vilcoq JR. Prognostic factors of breast recurrence in the conservative management of early breast cancer: a 25 -year follow-up. Int J Radiat Oncol Biol Phys 1989; 17:719-725.

11. Pezner RD, Lipsett JA, Desai K, Vora N, Terz J, Hill LR, Luk KH. To boost or not to boost: decreasing radiation therapy in conservative breast cancer treatment when "inked" tumor resection margins are pathologically free of cancer. Int J Radiat Oncol Biol Phys 1988; 14:873-877.

12. Hallahan DE, Michel AG, Halpern HJ, Awan AM, Desser R, et al. Breast conserving surgery and definitive irradiation for early stage breast cancer. Int J Radiat Oncol Biol Phys 1989; 17:1211-1216.

13. Schnitt SJ, Connolly JL, Harris JR, Hellman S, Cohen RB. Pathologic predictors of early local recurrence in stage I and II breast cancer treated by primary radiation therapy. Cancer 1984; 53:1049-1057.

14. Kaplan EL, Meier P. Non-parametric estimation from incomplete observations. J Am Stat Assoc 1958; 53:457-481.

15. Mantel N. Evaluation of survival data and two new rank order statistics arising in its consideration. Cancer Chemother Rep 1966; 50:163-170.

16. Cox DR. Regression models and life tables. JR Stat Soc Ser B 1972; 34:187-220.

17. Calle R, Vilcoq JR, Zafrani B, Vielh P, Fourquet A. Local control and survival of breast cancer treated by limited surgery followed by irradiation. Int J Radiat Oncol Biol Phys 1986; 12:873-878.

18. Amalric R, Santamaria F, Robert F, Siegle J, Altschuler C, et al. Radiation therapy with or without primary limited surgery for operable breast cancer: a 20 year experience at the Marseilles Cancer Institute. Cancer 1982; 49:30-34.

19. Delouche G, Bachelot F, Prement M, Kurtz JM. Conservative treatment of early breast cancer: long-term results and complications. Int J Radiat Oncol Biol Phys 1987; 13:29-34.

20. Leung S, Otmequine Y, Calitchi E, Mazeron, JJ, LeBourgeois JD, Pierquin B. Local-regional recurrences following radical external beam irradiation and interstitial implantation for operable breast cancer: a 23-year experience. Radiother Oncol 1986; 5:1-10.

21. Montague ED. Conservation radiation therapy in the treatment of operable breast cancer. Cancer 1984; 53:700-704.

22. Mustakallio S. Conservative treatment of breast carcinoma: review of 25 years follow-up. Clin Radiol 1972; 23:110-116.

23. Recht A, Silver B, Schnitt S, Connolly J, Hellman S, Harris JR. Breast relapse following primary radiation therapy for early breast cancer. I. Classification, frequency and salvage. Int J Radiat Oncol Biol Phys 1985; 11:1271-1276.

24. Sarrazin D, Le M, Rouesse J, Contesso G, Petit J, et al. Conservative treatment versus mastectomy in breast cancer tumors with microscopic diameter of 20 millimeters or less: the experience on the Institute Gustave-Roussy. Cancer 1984; 1209-1213.

25. Pierquin B. Conservative treatment for carcinoma of the breast: experience of Creteil ten-year results. In Harris JR, Hellman S, Silen W, eds. Conservative Management of Breast Cancer. Philadelphia: J.B. Lippincott, 1983, pp 11-14.

26. Prosnitz LR, Weshler Z, Goldenberg IS. Primary radiotherapy for breast carcinoma instead of mastectomy: the Yale experience. In Harris J, Hellman S, Silen W, eds. Conservative Management of Breast Cancer. Philadelphia: J.B. Lippincott, 1983, pp 61-70.

27. Fowble BL, Solin LJ, Schultz DJ, Goodman RL. Ten year results of conservative surgery and irradiation for stage I and II breast cancer. Int J Radiat Oncol Biol Phys 1991; 21:269-277.

28. Host H, Brennhaud IO, Loeb M. Postoperative radiotherapy in breast cancer-Long term results from the Oslo Study. Int J Radiat Oncol Biol Phys 1986; 12:727-732.

29. Rosenman JR, Bernard S, Kober C, Leland W, Varia M, Newsome $\mathrm{J}$. Local recurrences in patients with breast cancer at the North Carolina Memorial Hospital (1970-1982). Cancer 1986; 57:1421-1425.

30. Veronisi U, Salvador B, Luini A, Banfi A, Zucali R, et al. Conservative treatment of early breast cancer: long-term results of 1232 cases treated with quadrantectomy, axillary dissection, and radiotherapy. Ann Surg 1990; 211:250-259.

31. Fisher B, Redmon C, Poisson R, Margolese R, Wolmark N, et al. Eight-year results of a randomized clinical trial comparing total mastectomy and lumpectomy with or without irradiation in the treatment of breast cancer. N Engl J Med 1989; 822-828.

32. Calle R, Pilleron JP, Schlienger P, Vilcoq JR. Conservative management of operable breast cancer: ten-year experience at the Foundation Curie. Cancer 1978; 42:2045-2053.

33. Fisher E, Sass R, Fisher B, Gregorio R, Brown R, Wickerham L, and collaborating NSABP Investigators. Pathologic findings from the National Surgical Adjuvant Breast Project (Protocol 6) II. Relation of local breast recurrence to multicentricity. Cancer 1986; 57:1717-1724.

34. Olivotto IA, Rose MA, Osteen RT, Love S, Cady B, et al. Late cosmetic outcome after conservative surgery and radiotherapy: analysis of causes of cosmetic failure. Int J Radiat Oncol Biol Phys $1989 ; 17: 747-753$.

35. Van Limbergen E, van der Schueren E, Lerut T, Christiaens R. Cosmetic evaluation of breast conserving treatment for mammary cancer. 2. A quantitative analysis of the influence of radiation dose, fractionation schedules and surgical treatment techniques on cosmetic results. Radiother Oncol 1989; 16:253-267. 